The authors reported no conflicts of interest.

The Journal policy requires editors and reviewers to disclose conflicts of interest and to decline handling or reviewing manuscripts for which they may have a conflict of interest. The editors and reviewers of this article have no conflicts of interest.

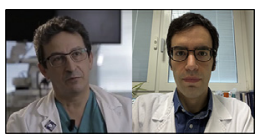

\section{REPLY: WILL THE NEW TOOL USED FOR CEREBRAL PERFUSION BE ABLE TO "KEEP IT}

\section{SIMPLE" OR NOT?}

\section{Reply to the Editor:}

We appreciate the comments provided by the authors about the new AV Flow cannula (MedEurope Srl, Bologna, Italy), used for antegrade selective cerebral perfusion in arch surgery. They better clarify the positive features of this interesting device, including the possibility of guidewire introduction and suture of epiaortic vessels in the graft without having the bulk of the cannula. ${ }^{1}$ Nevertheless, a very important concept to observe in surgery is to standardize and simplify the procedure to reduce complications and achieve durable outcomes, especially in complex scenarios. It is the reason why we strongly believe in the "keep it simple" principle applied to open arch repair. To achieve this goal, a meticulous preoperative planning is mandatory for every aortic procedure. Regarding aortic arch surgery, the selection of a central cannulation site for cardiopulmonary bypass is crucial to obtain a safe unilateral antegrade cerebral perfusion throughout the entire hypothermic circulatory arrest time, regardless of insertion and removal of the cannula. Using this principle, you are halfway to being successful.

The new tool has the potential to be an attractive one in the antegrade selective cerebral perfusion arsenal, but the primary limitation remains the traumatic injury created in the arterial wall during the insertion and removal (closure of purse string) of the cannula. Arch vessels can be fragile and most of the time involved in the primary arch disease; moreover, it is quite easy to cause soft plaque mobilization and arterial lesions. In a similar maneuver used for the delivery of supra-aortic inner branches in double-branched arch procedures, it has been reported that wire and graft manipulation contribute to the risk of cerebral embolism and stroke. ${ }^{2,3}$

Moreover, as previously pointed out, ${ }^{4}$ there are relative contraindications for the use of this new cannula in the case of direct involvement and dissection of supra-aortic vessels either for acute and chronic aortic dissections or severe atherosclerotic arches. In summary, as for every new device introduced in the market, the new interesting tool well-described by Venturini and colleagues ${ }^{5}$ will prove its effort over time with standardization of care.

Giacomo Murana, $M D, P h D^{a}$

Davide Pacini, $M D, P h D^{a, b}$

${ }^{a}$ Division of Cardiac Surgery

Cardiac Surgery Department

IRCCS

Azienda Ospedaliero-Universitaria di Bologna

${ }^{b}$ Department of Experimental

Diagnostic and Specialty Medicine

DIMES

University of Bologna

Bologna, Italy

\section{References}

1. Venturini A, Gallingani A. Letter to the Editor: a new tool in the arsenal. J Thorac Cardiovasc Surg Tech. 2021;9:33-4.

2. Di Marco L, Murana G, Lovato L, Gliozzi G, Buia F, Attinà D, et al. Endovascular solutions for aortic arch diseases: total and hybrid. Surg Technol Int. 2021;38. sti38/1415.

3. Tsilimparis N, Detter C, Law Y, Rohlffs F, Heidemann F, Brickwedel J, et al. Sin gle-center experience with an inner branched arch endograft. J Vasc Surg. 2019; 69:977-85.

4. Murana G, Leone A, Pacini D. Commentary: antegrade cerebral perfusion using a "new" cannula: keep it simple! J Thorac Cardiovasc Surg Tech. 2020;4:14-5.

5. Venturini A, Gallingani A, Asta A, Cannarella AM, Zanchettin C, Zoffoli G, et al A new cannula for antegrade selective cerebral perfusion. J Thorac Cardiovasc Surg Tech. 2020;4:10-3.

https://doi.org/10.1016/j.xjtc.2021.08.001
Copyright (C) 2021 The Author(s). Published by Elsevier Inc. on behalf of The American Association for Thoracic Surgery. This is an open access article under the CC BY-NC-ND license (http://creativecommons.org/licenses/by-nc-nd/4.0/). 